\title{
A green building information modelling approach: building energy performance analysis and design optimization
}

\author{
Shang-yuan Chen $^{\mathrm{a}}$ \\ School of Architecture, Feng Chia University, Taiwan.
}

\begin{abstract}
This study concerning green BIM focuses on the integrated application of Building Information Modelling (BIM) and building performance analysis (BPA) software as tools for the design and analysis of building projects, and employs a sequential decision-making cycle and continuously improving design to achieve an optimal proposal consistent with environmental effectiveness. Taking a new Taichung hotel construction project energy consumption design optimization as an example, this study relied on the steps of (1) Determination of the scope of discussion of the proposal within the building life cycle, (2) Setting of energy conservation targets, (3) Accessing to external climate data, (4) Entering internal settings, (5) Implementation of energy conservation calculation module, (6) Visualization analysis and hot spot tracking (7) Proposal Revision, and (8) Optimal proposal, to verify the green BIM concept. With regard to the setting of energy conservation targets, this study recommends that building energy use intensity (EUI) be used as an energy load measurement unit of integrated performance indicators, and employs performance optimization percentage as a rating criterion. In accordance with this method, green BIM combined with assessment of green building indicators is as a means of facilitating integrated design and analysis decision-making.
\end{abstract}

\section{Motivation and goals}

In the face of a rapidly changing climate and global energy crises, how to use building information modelling (BIM) tools to obtain architectural designs offering environmental effectiveness has become a leading issue in the contemporary architectural and construction industries. BIM has two implications, one of which is information modelling, and the other of which is information management. Along related lines, building performance analysis (BPA) software provides building performance visualization and data processing analysis capabilities. Green BIM consequently emphasizes the effective combination of BIM and BPA technologies in integrated design, and seeks to promote a rational building design and analysis decision-making cycle and continuously improving design to ensure the optimized development of designs offering better environmental effectiveness. However, the implementation of green BIM is not a trivial task, and further research and investigation is needed in the areas of software tool selection and integration, and establishment of integrated design procedures and optimal criteria.

\footnotetext{
${ }^{a}$ Corresponding author : shangyuanc@gmail.com
} 


\section{Literature review}

The chief categories of green BIM research include BIM and BPA, as well as the integration and application of BIM and BPA in sustainable building design.

The book "Green BIM-Successful Sustainable Design with Building Information Modelling" proposed the "green BIM" concept for the first time, explored the influence of BIM on the improvement of design methods and various construction industry participants, and employed BIM in conjunction with BPA to promote the development of sustainable design [1]. McGraw-Hill Construction suggests that green BIM can employ energy modelling together with BIM tools to greatly enhance sustainable design results [2].

Building Product Models, published by Eastman in 1999 defined building product model concepts, technologies, and standards, and set the stage for BIM [3]. Eastman's BIM Handbook defined BIM and related technologies, and provided BIM applications and illustrative cases for various types of participants (project owners, project managers, designers, engineers, and contractors, etc.) [4].

BPA, also known as building performance simulation (BPS), relies on computer software to predict building performance and output visualized images, data, statistical analysis charts, and forms resulting from simulation. BPA can help users to understand the performance of their design proposals, which will facilitate design decisions and provide a basis for the continuing optimization of design proposals. The focus of building simulation work consisted of building heat dissipation performance during the 1960s and '70s, and simulation was employed to perform thermal load calculations and energy conservation analysis $[5,6]$. The focus shifted from energy consumption to many other building performance characteristics during the early 1990s [7], including the use of integrated modelling to assess heat and mass transfer, air flow, and visual and acoustic performance. To date, the use of BPA in conjunction with BIM tools try to establish integrated design and analysis decisionmaking procedures [8].

Green BIM emphasizes the combination of BIM and BPA software technologies in order to perform integrated design, and seeks to promote a rational building design and analysis decisionmaking cycle in order to ensure the optimized development of designs offering better environmental effectiveness. In the article "Building Performance Analytics: Establishing a Methodology of Design Integration," Andrasik (2015)[9] further stresses that the mission of BPA lies at the intersection of BIM and sustainable design, and the implementation of BPA tasks begins during the early design stage in sustainable design. When employed in conjunction with BIM-based design methods, BPA enables the assessment and comparison of the building performance of different design proposals, can help guide decisions, and can effectively improve construction projects [10] (Figure 1).

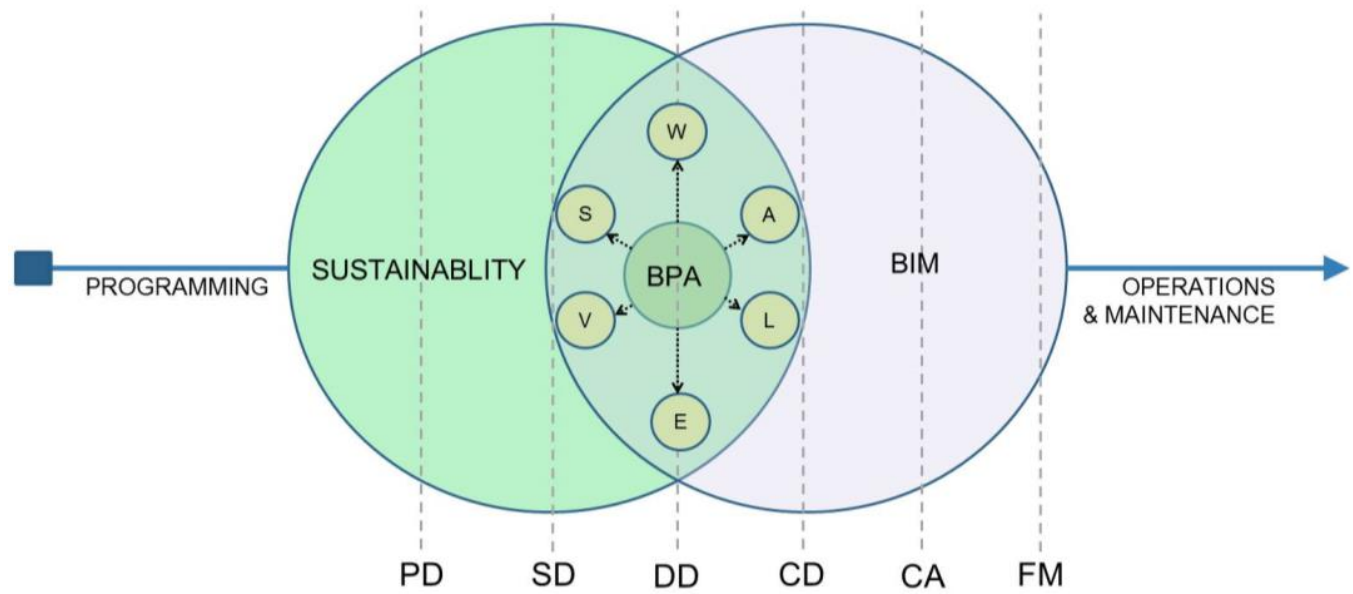

Note: Pre-Design (PD), Schematic Design (SD), Design Development (DD), Construction Detailing (CD), Construction Administration (CA), and Facility Management (FM)

Figure 1. Linkage between sustainable design, BPA, and BIM. 
Apart from use in obtaining 3-D geometric information, BIM can also be used to formulate that part of non-geometric information that can be easily transmitted to BPA software. BIM system software companies are also incorporating BPA tools within the scope of their software development and integration efforts, and hope that they can help designers and other personnel to precisely control building performance within a 3-D operating environment in order to achieve sustainability. Examples include Autodesk ${ }^{\circledR}$ Ecotect Analysis [11] and even easier-to-use Energy Analysis for Revit [12]; Bently ${ }^{\circledR}$ Hevacomp [13] series and Tas ${ }^{\circledR}$ building modelling and simulation tool [14]; and Graphisoft ${ }^{\circledR}$ Eco Designer Star [15]. Table 1 summarizes and compares software programs, supported file formats, visualization items, and performance analysis items. The compared BPA items include natural and artificial lighting, indoor lighting, overshadowing and shading analysis, solar radiation and thermal performance analysis, wind ventilation analysis, acoustic analysis, visual access, energy load, carbon emission analysis, and whole building energy performance simulation, etc.

Table 1. BPA software comparison

\begin{tabular}{|c|c|c|c|c|c|}
\hline $\begin{array}{c}\text { Software } \\
\text { tools }\end{array}$ & Engine & $\begin{array}{c}\text { Import } \\
\text { file } \\
\text { formats }\end{array}$ & Visualization items & BPA items & $\begin{array}{c}\text { export } \\
\text { file } \\
\text { formats }\end{array}$ \\
\hline $\begin{array}{l}\text { Autodesk }^{(B)} \\
\text { Energy } \\
\text { Analysis for } \\
\text { Revit } \\
\end{array}$ & DOE-2 & $\begin{array}{l}\text { form } \\
\text { Revit }\end{array}$ & Energy Analysis Result & Energy Analysis & gbXML \\
\hline $\begin{array}{l}\text { Autodesk }^{B} \\
\text { Ecotect } \\
\text { Analysis }\end{array}$ & $\begin{array}{c}\text { CIBSE, } \\
\text { Split-Flux }\end{array}$ & $\begin{array}{l}\text { dxf/3ds/ } \\
\text { rvt- } \\
\text { gbXML/ } \\
\text { skp-obj }\end{array}$ & $\begin{array}{c}\text { Solar radiation, } \\
\text { shadows, natural } \\
\text { lighting, thermal } \\
\text { simulation and analysis, } \\
\text { building energy load } \\
\text { analysis }\end{array}$ & $\begin{array}{l}\text { Exports to Green Building } \\
\text { Studio, can perform } \\
\text { reporting of carbon } \\
\text { emissions, water usage, and } \\
\text { costs }\end{array}$ & $\begin{array}{l}\text { gbXML/ } \\
\text { idf/ inp/ } \\
\text { dxf }\end{array}$ \\
\hline $\begin{array}{l}\text { Bently }^{(B)} \\
\text { Hevacomp } \\
\text { Dynamic } \\
\text { Simulation }\end{array}$ & $\begin{array}{c}\text { EnergyPlu } \\
\mathrm{s}\end{array}$ & $\begin{array}{l}\text { dxf/ dgn/ } \\
\mathrm{dwg} / \mathrm{ifc} / \\
\mathrm{skp} / 3 \mathrm{ds} / \\
\operatorname{cis} 2 / \\
\mathrm{gbXML}\end{array}$ & $\begin{array}{l}\text { Energy analysis, three- } \\
\text { dimensional } \\
\text { visualization of external } \\
\text { shading, indoor sunlit } \\
\text { areas }\end{array}$ & $\begin{array}{c}\text { Calculation of building } \\
\text { heating and cooling loads, } \\
\text { calculation of pipe and duct } \\
\text { system dimensions, carbon } \\
\text { emission analysis }\end{array}$ & $\begin{array}{l}\text { Idf/ dwg/ } \\
\text { dgn/ skp/ } \\
\text { IFC }\end{array}$ \\
\hline $\begin{array}{c}\text { Tas }{ }^{(B)} \\
\text { building } \\
\text { modeling and } \\
\text { simulation } \\
\text { tool }\end{array}$ & $\begin{array}{c}\text { TAG } \\
\text { simulator }\end{array}$ & $\begin{array}{l}\mathrm{dwg} / \\
\mathrm{gbXML} / \\
\text { inp/idf }\end{array}$ & $\begin{array}{l}\text { Daylighting, wind } \\
\text { tunnel analysis, } \\
\text { simulation of hot zones }\end{array}$ & $\begin{array}{l}\text { Carbon emissions, energy } \\
\text { consumption analysis, cost } \\
\text { analysis, indoor comfort } \\
\text { indices }\end{array}$ & gbXML \\
\hline $\begin{array}{l}\text { Graphisoft }^{(R)} \\
\text { EcoDesigner } \\
\text { STAR }\end{array}$ & $\begin{array}{l}\text { StruSoft's } \\
\text { VIPcore } \\
\text { calculatio } \\
\text { n engine }\end{array}$ & $\begin{array}{l}\text { from } \\
\text { ArchiCA } \\
\text { D }\end{array}$ & $\begin{array}{c}\text { Meteorological data } \\
\text { analysis, energy load } \\
\text { analysis, thermal bridge } \\
\text { analysis }\end{array}$ & $\begin{array}{l}\text { Building energy load } \\
\text { analysis, energy } \\
\text { optimization settings, } \\
\text { renewable energy programs }\end{array}$ & $\begin{array}{l}\text { gbXML/ } \\
\text { PHPP/ } \\
\text { Isbem/ } \\
\text { VIP- } \\
\text { Energy }\end{array}$ \\
\hline
\end{tabular}

This study uses assessment of building energy consumption as an example to illustrate the application of green BIM in integrated design procedures and employees Autodesk ${ }^{{ }_{1}}$ s Energy Analysis for Revit as a validation tool. This software was chosen for the following three reasons:

(1) Energy Analysis for Revit consists of a BIM tool combined with a BPA tool, and possesses a user-friendly interface suitable for architects and designers

(2) The validation of its DOE-2 engine has earned considerable credibility

(3) The virtual weather station technology developed by Autodesk ${ }^{\circledR}$ can overcome the past problem that local climate data is not easy to acquire (this is described in detail in the third section)

Most of the BPA software and 3D modeling software are separated; files' interoperation and integration between them are inconvenient. With regard to energy consumption analysis software, because of the complexity of building energy forecasting, energy simulation tools usually consist of two parts. The first part is the engine, which includes formulas and procedures, and the second part is 
the user interface, which allows the input of parametric data and displays results. Architectural design simulation engines chiefly serve to support building design and analysis via the comparison of the energy consumption of different design proposals. While most simulation engines have been developed by academic or research organizations, most user interfaces have been realized by private software companies [16] and the combination of the two parts forms the main BPA software on the market (ex. RIUSKA, eQUEST, and Design Builder, etc.) (Figure 2). However, Autodesk ${ }^{\circledR}$ s Energy Analysis for Revit integrates energy performance analysis with BIM software. In the Revit platform, energy analysis includes a set of program commands, and Revit relies on the Green Building Studio (GBS) cloud service to transmit information input or created on the Revit platform, including (1) building geometric information, (2) location and climate data, and (3) non-geometric attributes and parameters, to the GBS DOE-2 simulation engine in gbXML format, and also transmit results back to the Revit platform for display. In other words, the BIM-Revit platform integrates BIM modeling and the GBS performance simulation service, and thus provides a replacement for the BPA software used as a user interface in the past (Figure 3) [17].

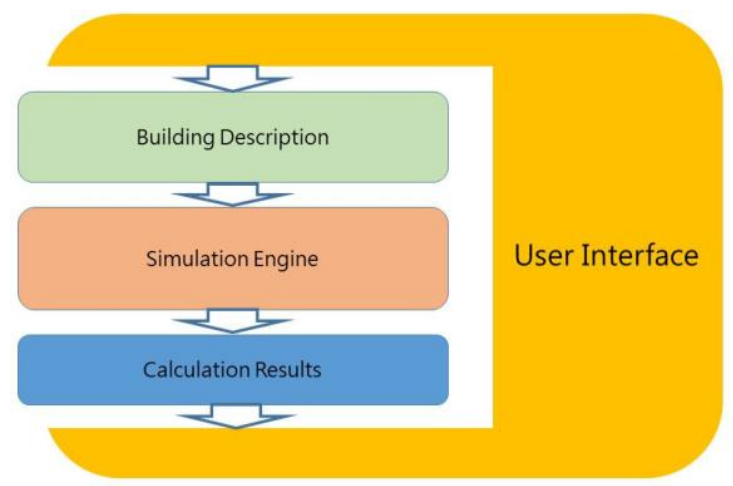

Figure 2. A BPA tool architecture [16].

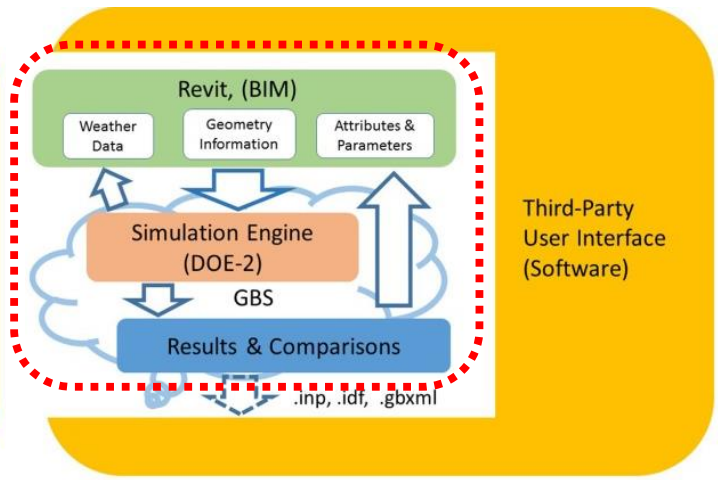

Figure 3. Relationship between Revit, Energy Analysis, GBS, and third party user interface.

\section{Theory and method}

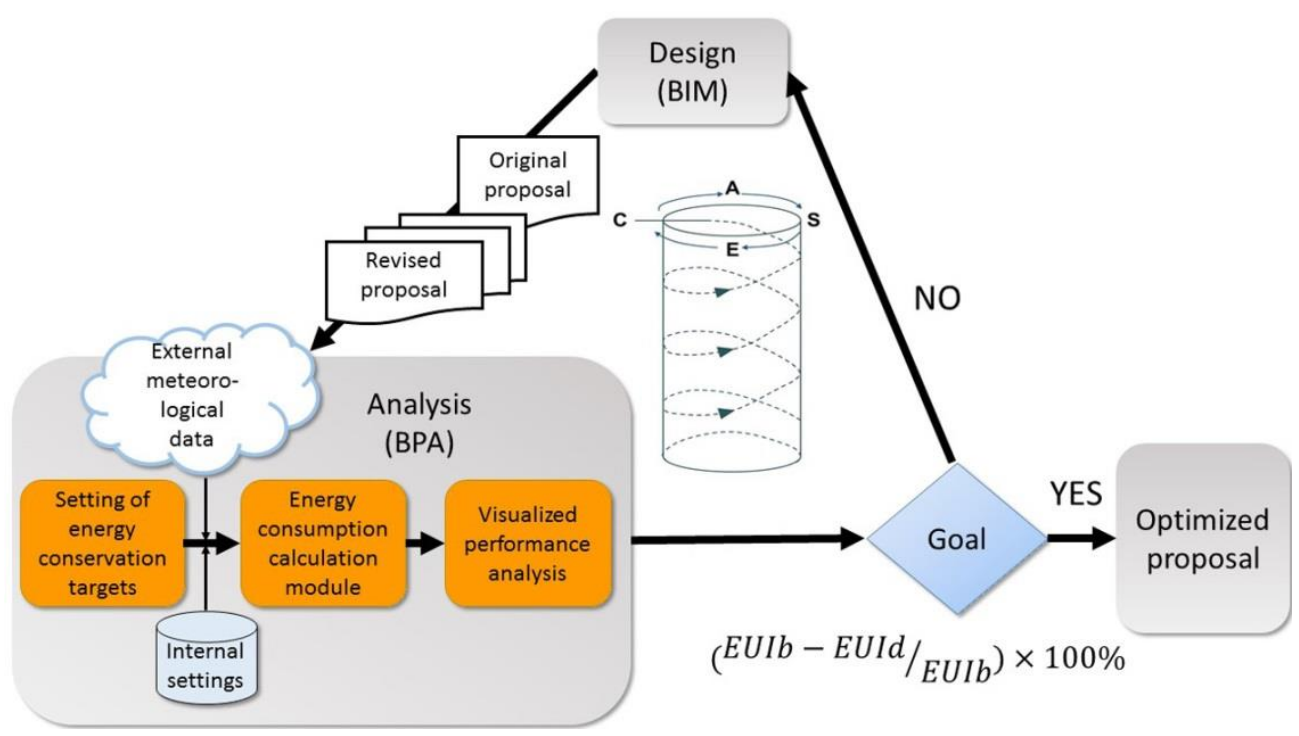

Figure 4. A green BIM-based decision-making cycle model. 
As summarized above, green BIM emphasizes the use of BIM as a basic tool from the start of the design process. Responding to localized climate conditions, BPA was implemented via a decisionmaking cycle consisting of design and analysis steps, and continued design optimization performed to obtain an optimal proposal meeting the need for environmental effectiveness, which ultimately achieved the goal of environmental sustainability. A model of the green BIM-based decision-making cycle is shown in Figure 4.

Energy consumption analysis consisted of the following processes:

(1) Determination of the scope of discussion of the proposal within the building life cycle: The simulation software employed by this study calculated the building's energy consumption during the operating stage. And the decision-making cycle for performance analysis and optimization design occurred in the early design stage (including schematic design (SD) and design development (DD) stages). The first step was to find the optimal proposal for different configurations of the conceptual massing during the SD stage in accordance with the target of performance optimization percentage. Detailed building elements were added during the DD stage, and element attributes and parameters were adjusted to ensure the continued optimization of performance (Figure 5).

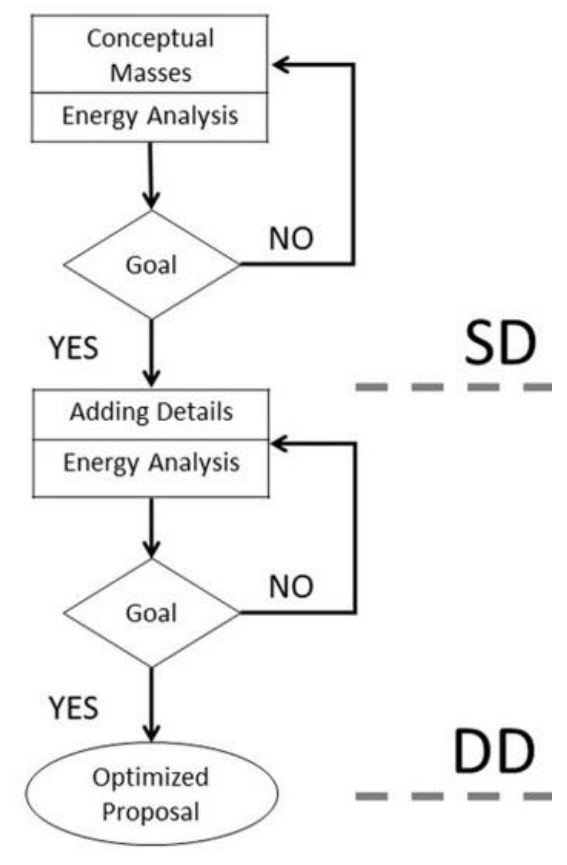

Figure 5. Design decision-making cycle (SD DD).

(2) Setting of energy conservation targets:

After consulting reference information Leadership in Energy and Environmental Design (LEED) [18] and the Taiwan Power Cost and Price tips [19], this study suggest using energy use intensity (EUI), which is annual power consumption per unit area of the building, as an energy load measurement unit and integrated energy conservation performance indicator. In accordance with the corresponding building use classification and type in the "EUI values for various types of Buildings" (Table 2) issued by the Bureau of Energy, Ministry of Economic Affairs (MOEA), R.O.C., the study decided to take the relevant average value as a common benchmark value for project design [20]. The performance optimization percentage, which served as a target setting or rating criterion, was obtained from the ratio of the difference between the common benchmark EUIb value and optimized project EUId value of the common benchmark EUIb.

$$
\text { Performance optimization percentage }=(E U I b-E U I d / E U I b) \times 100 \%
$$


Table 2. EUI Values for Various types of Buildings.

\begin{tabular}{clccc}
\hline Building use classification & \multicolumn{3}{c}{ EUI } \\
\cline { 2 - 5 } & & $\begin{array}{c}\text { Average } \\
\text { value }\end{array}$ & $\begin{array}{c}\text { Minimum } \\
\text { value }\end{array}$ & $\begin{array}{c}\text { Maximum } \\
\text { value }\end{array}$ \\
\hline Main category & Subcategory & $(\mathrm{kWh} / \mathrm{m} 2 \cdot \mathrm{yr})$ & $(\mathrm{kWh} / \mathrm{m} 2 \cdot \mathrm{yr})$ & $(\mathrm{kWh} / \mathrm{m} 2 \cdot \mathrm{yr})$ \\
\hline \multirow{2}{*}{$\begin{array}{c}\text { Government } \\
\text { agencies }\end{array}$} & Central (general administration) & 114.1 & 36.6 & 189.8 \\
\cline { 2 - 5 } & Local (general administration) & 87.1 & 37.7 & 134.4 \\
\hline \multirow{3}{*}{ Schools } & General universities & 84.4 & 45.7 & 123.4 \\
\cline { 2 - 5 } & Technical universities & 69.0 & 33.0 & 99.4 \\
\cline { 2 - 5 } & High schools & 65.4 & 30.4 & 107.0 \\
\cline { 2 - 5 } & Vocational schools & 59.3 & 30.4 & 98.4 \\
\hline Office high-rises & & 149.8 & 79.2 & 225.0 \\
\hline \multirow{2}{*}{ Hotels } & International tourist hotels & 207.6 & 117.6 & 299.2 \\
\cline { 2 - 5 } & General tourist hotels & 198.8 & 106.8 & 264.0 \\
\cline { 2 - 5 } & General hotels & 195.6 & 172.9 & 223.6 \\
\hline
\end{tabular}

Notes: Energy consumption indicator calculations include indoor parking facilities. [21]

(3) Accessing to external meteorological data:

BPA software requires representative climate data as basic information for environmental simulation and energy calculations. Because of insufficient local climate data, the application of past BPA software was limited. Due to breakthroughs in cloud computing-based virtual weather stations technology, however, green BIM is not limited to application in certain regions. Autodesk ${ }^{\circledR}$ s $s$ weather data database includes data from both physical weather stations and virtual weather stations. Autodesk $^{\circledR}$ s data is in the internationally-accepted TMY2 (typical meteorological year) format. Employing TMY2 data for each weather station, Autodesk ${ }^{\circledR}$ derives the corresponding data for virtual weather stations through simulations, which helps compensate for differences in data between real weather stations and shrinks the distance between meteorological grid points to less than $14 \mathrm{~km}$, which boosts modeling accuracy [22].

(4) Entering Internal settings:

In accordance with Anderson (2014a)[23], factors influencing energy consumption during the building use stage include geometric shape information in the BIM model and non-geometric information (attributes and parameters) required by BIM or BPA, including building type, activity types, user density, shell attributes (structural materials, thermal conductivity, insulation factor), and active systems (air conditioning and lighting). Parameter settings for these items are entered in BIM or BPA software, and the parameter values input for the initial proposal must comply with the lowest standards of local building codes. The settings input for the later optimized proposal must also be within the scope permitted by law.

(5) Implementation of energy conservation calculation module:

As shown in the diagram (Fig.3), Revit and Energy Analysis for Revit software upload the model's geometric information and non-geometric internal settings (performance parameters), and climate data to GBS in the gbXML format, and GBS uses the DOE-2 engine to perform energy consumption analysis.

(6) Visualization analysis and hot spot tracking:

Following processing via the cloud DOE-2 simulation engine, the results of visualization analysis are transmitted back to the user, including such building performance values as performance simulation results and various numerical analyses and statistical tables. Hot spot tracking is performed by preliminarily determining variables that have a major influence on energy consumption from the results of visualization analysis, where these variables can provide a basis for subsequent proposal revision.

(7) Proposal Revision:

The controlling variables are adjusted on the basis of the results of visualization analysis and hot spot tracking, and a revised proposal submitted. 
(8) Optimal proposal:

If a revised proposal fails to comply with the target settings, return to Step (4) and repeat steps (4)-(7), until an optimal proposal has been obtained target settings.

\section{Empirical verification}

This study used the BPA and design optimization process for a new Taichung hotel construction project to implement and verify a green BIM-based decision-making cycle model.

(1) Determination of the scope of project discussion within the building life cycle:

The green BIM-based decision-making cycle for the new Taichung hotel construction project took place during the initial design stage (from the SD to the DD stage). Optimization of conceptual massing was first performed during the SD stage, and the DD stage. Details were added to optimal proposals selected during the SD stage, and continued optimization performed during the DD stage.

(2) Setting of energy conservation targets:

In the study case, the energy conservation target set during the SD stage consisted of a performance optimization percentage of $21 \%$, which implied a $21 \%$ or better improvement over the common benchmark. And during the DD stage, the performance optimization percentage was increased by a further $5 \%$.

(3) Accessing to external meteorological data:

Taking a site in Taichung's Beitun District as an example after inputting the latitude and longitude of the site location, GBS. automatically transmits TMY2 climate data for the closest weather station (Figure 6).

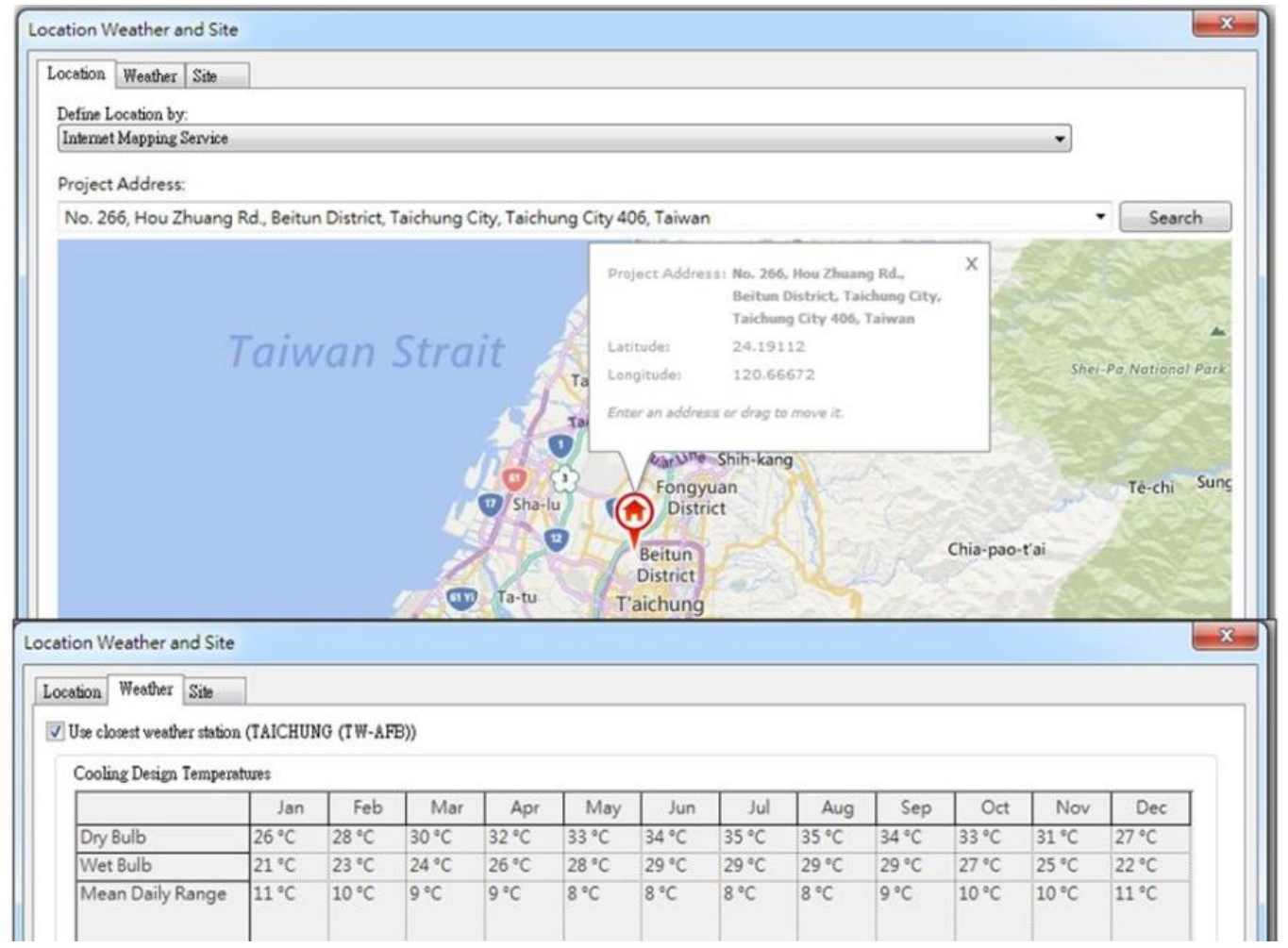

Figure 6. Site location settings and weather station TMY2 climate data.

(4) Entering Internal settings:

A model of the initial proposal was created (Create Mass/Place Mass) (Figure 7), and simple modeling was performed directly in Revit. After first establishing geometric information in the form of the 
massing and floors, the initial proposal was modeled based on default values. The building type was "hotel building," the percentage glazing was set at $40 \%$. Building operating details: refers to the number of hours of operation each week, where 12/7 indicates the building was used 12 hours per day, seven days a week. HVAC system: refers to the choice of HVAC system used in the model for energy analysis; the default choice was central VAV, hot water heating, 5.96 COP refrigerator, and boiler with an efficiency of 84.5. External ventilation information: refers to the amount of external air flow required by each person, air exchange rate per unit area, and ventilation rate per hour. The other construction material options employed the default values in the BIM model (Table 3). After performing settings, the model was converted to an energy analysis model (Figure 8).

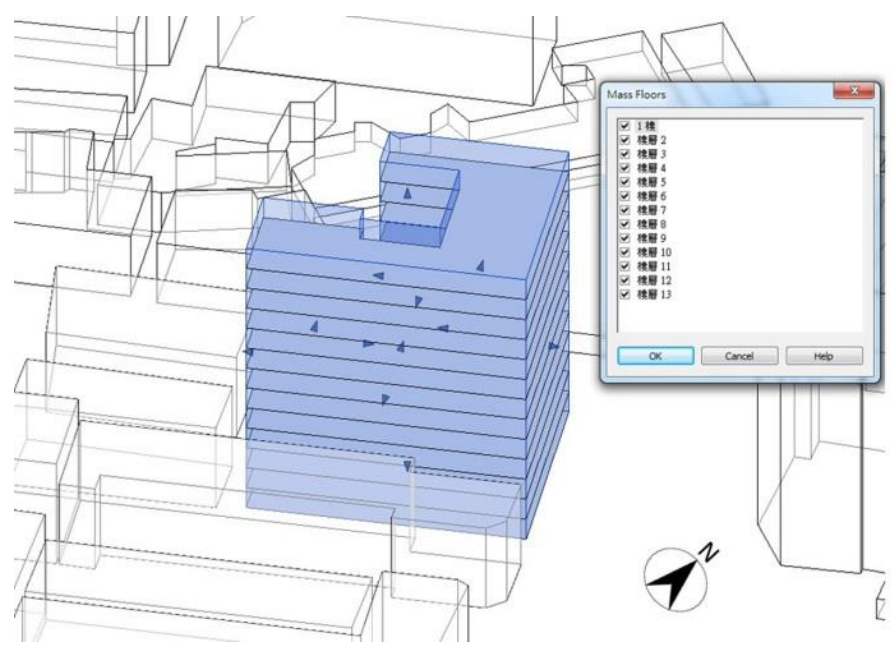

Figure 7. Mass model of project, including floors (geometric information).

Table 3. Internal settings of building.

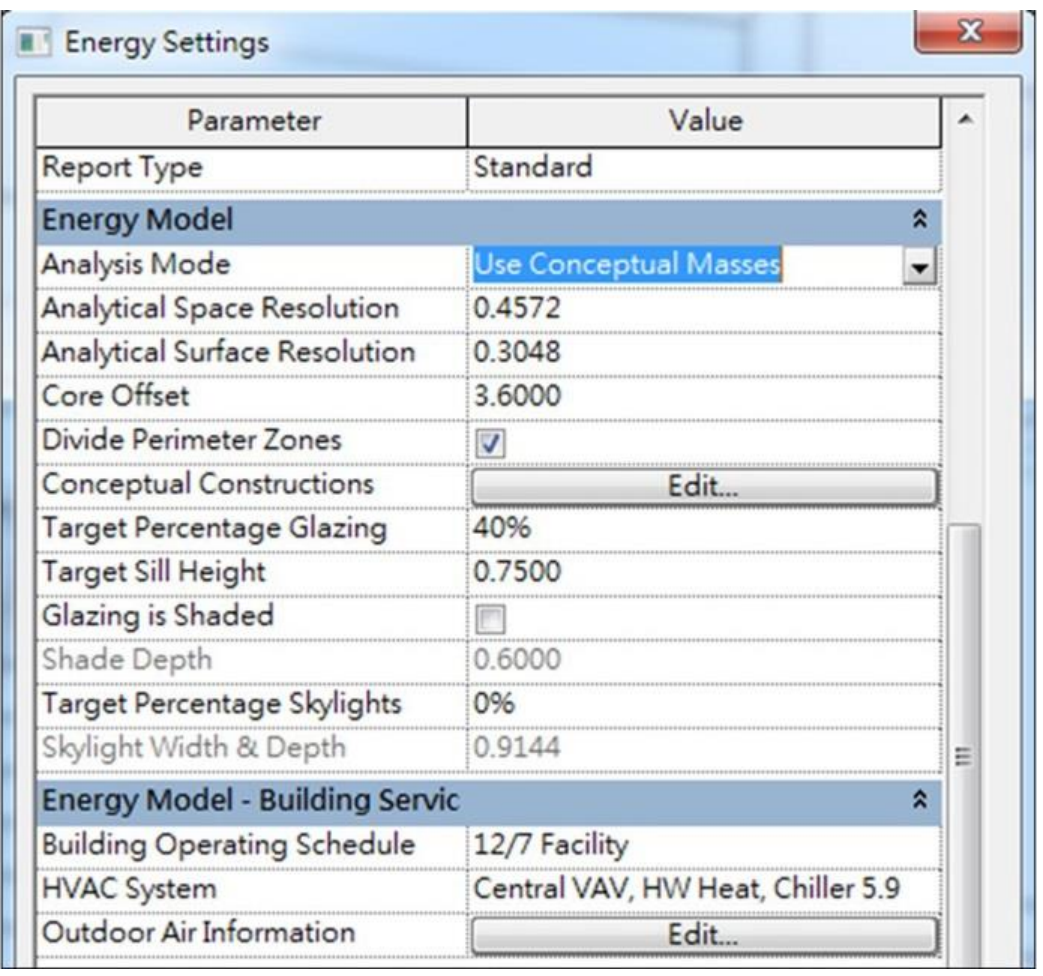




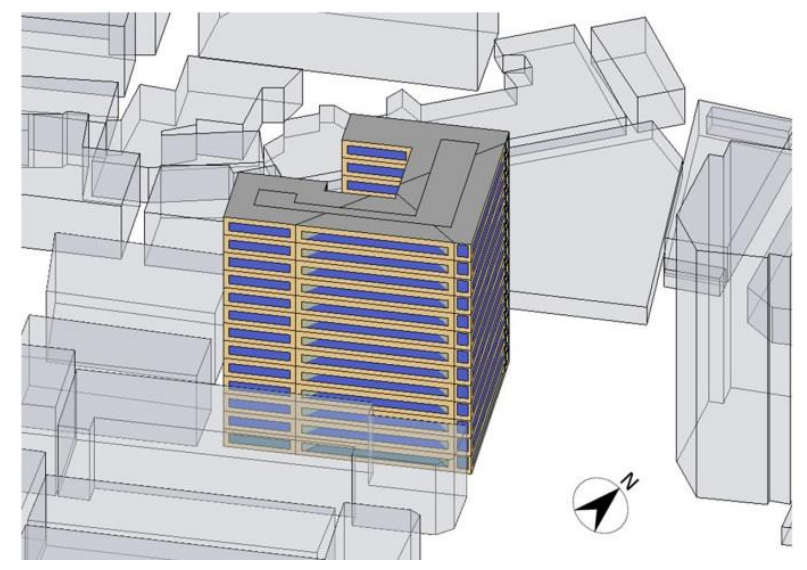

Figure 8. Conversion to an energy analysis model.

(5) Implementation of energy conservation calculation module:

The information model and internal settings and climate data are transmitted in gbXML format to the cloud GBS's DOE-2 engine for computation, and the visualized performance analysis results are transmitted back.

(6) Visualization analysis and hot spot tracking:

- Visualization analysis :

Items includes analysis of site climate conditions, building energy use performance, and the building's physical environment. The results of analysis can serve as a reference for subsequent revisions of the proposal. Apart from the TMY2 climate data provided by weather stations in Step (3), site climate analysis also includes wind rose charts (Figure 9), which are provided within visualization analysis tables. Building energy use analysis and building physical environment analysis include such items as EUI, building life cycle (30 years) energy consumption and cost calculations, energy recovery/conservation potential, average carbon emissions, monthly air conditioning load, and peak power demand.

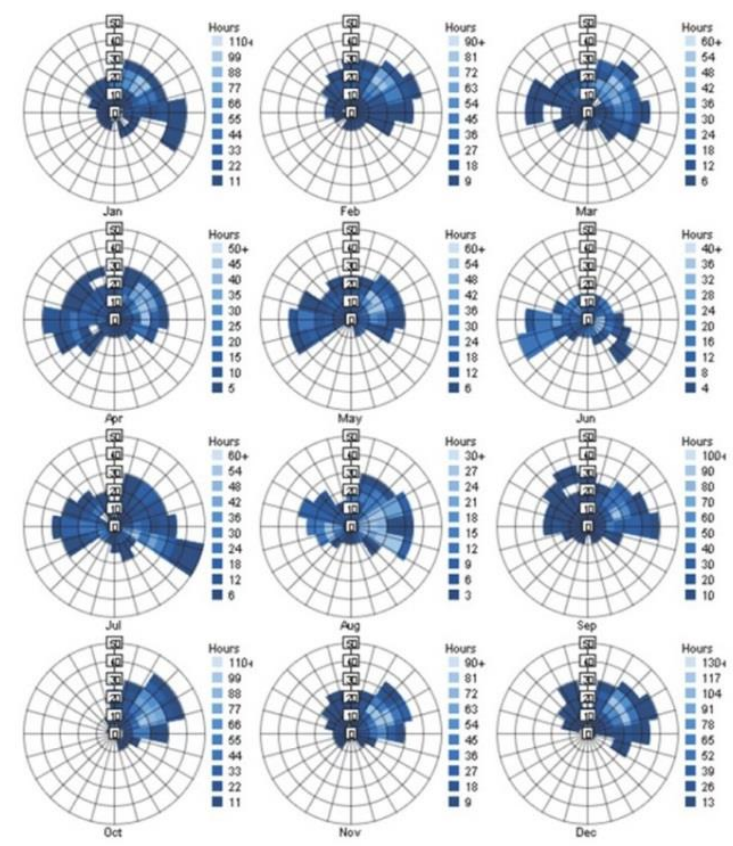

Figure 9. Mothy Wind Roses. 
Hot spot tracking :

Building performance calculation results can be reviewed in connection with target settings, and key factors determined for use as a basis for revision. Different types of buildings have different energy consumption characteristics. The assessment of EUI must be based on a comparison with other buildings with the same operating mode to be fully meaningful. In accordance with simulation results, the initial proposal had an EUI value of $204 \mathrm{kWh} /, \mathrm{m} 2 \cdot \mathrm{yr}$ (Tables 4), which was less than common benchmark value of $198.8 \mathrm{kWh} / \mathrm{m} 2 * \mathrm{yr}$, general tourist hotels, after checking in the EUI values for various types of Buildings issued by the Bureau of Energy, MOEA (Tables 2). The building's optimized energy performance was calculated to be $-2.9 \%$, which was less than the preset target value of $21 \%$. And according to the results of power usage ratio analysis, air conditioning equipment had the highest energy consumption (46\%), followed by lighting equipment with $21 \%$ (Figure 10). Energy load composition analysis indicated that sunlight through windows and window heat conduction were the largest sources of air conditioning load, followed by lighting equipment and solar radiation through windows. Since the latter two sources were mutually correlated factors, experimentation during the revision process was used to refine the design proposal and achieve better energy conservation. In addition, monthly power usage distribution revealed that energy consumption was relatively high during the summer months of July and August (Figure 11), which indicated that improvement of power usage during summer could reduce operating load.

Table 4. The initial project (CD)

\section{Building Performance Factors}

\begin{tabular}{ll} 
Location: & Taichung, Taiwan \\
\hline Weather Station: & 548644 \\
\hline Outdoor Temperature: & Max: $35^{\circ} \mathrm{C} / \mathrm{Min}: 8^{\circ} \mathrm{C}$ \\
\hline Floor Area: & $8,298 \mathrm{~m}^{2}$ \\
\hline Exterior Wall Area: & $5,840 \mathrm{~m}^{2}$ \\
\hline Average Lighting Power: & $9.69 \mathrm{~W} / \mathrm{m}^{2}$ \\
\hline People: & $332 \mathrm{people}$ \\
\hline Exterior Window Ratio: & 0.40 \\
\hline Electrical Cost: & $\$ 0.06 / \mathrm{kWh}$ \\
\hline Fuel Cost: & $\$ 1.20 /$ Therm \\
\hline
\end{tabular}

\section{Energy Use Intensity}

\begin{tabular}{ll} 
Electricity EUI: & $204 \mathrm{kWh} / \mathrm{sm} / \mathrm{yr}$ \\
\hline Fuel EUI: & $42 \mathrm{MJ} / \mathrm{sm} / \mathrm{yr}$ \\
\hline Total EUI: & $778 \mathrm{MJ} / \mathrm{sm} / \mathrm{yr}$ \\
\hline
\end{tabular}

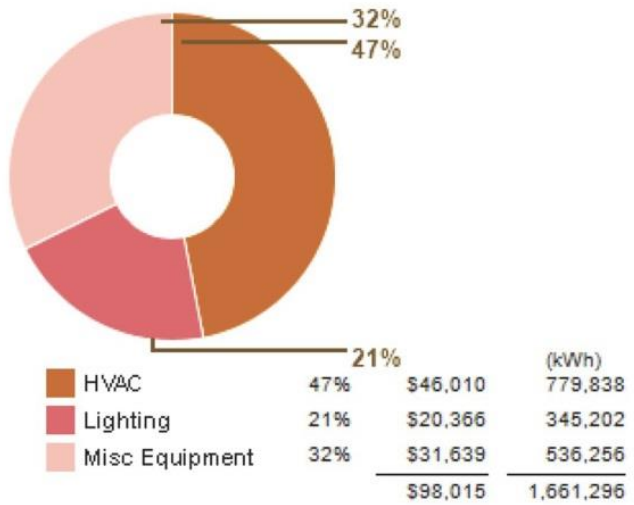

Figure 10. Analysis of Energy Use: Electricity.

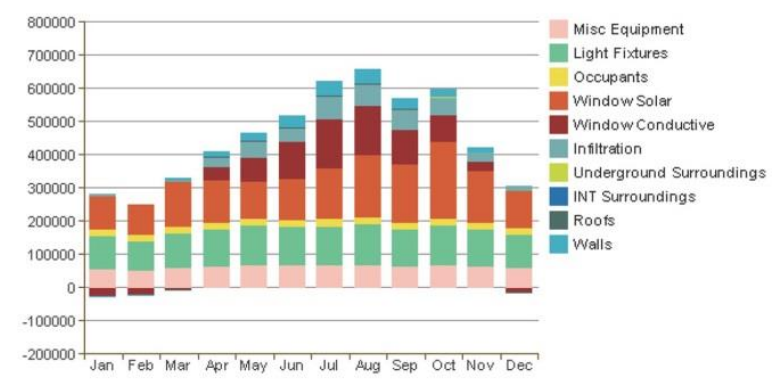

Figure 11. Review of monthly cooling load. 
(7) Proposal revision:

According to passive building design principles, the monsoon seriously affects air convection and occupants' comfort of the building volume and its open space. According to the wind rose, the site would typically receive $\mathrm{W}$ and SW monsoon winds in the summer and NE monsoon winds in the winter (Figure 13). A discussion of the relationship between the building mass and outdoor space was conducted to ensure that the project's open spaces would face the wind in the summer, and be sheltered from the wind in the winter. Several rounds of revision and assessment were performed, which involved repeated implementation of steps (4)-(8), and revision continued until a proposal meeting the preset energy conservation targets was obtained (Figure 13).

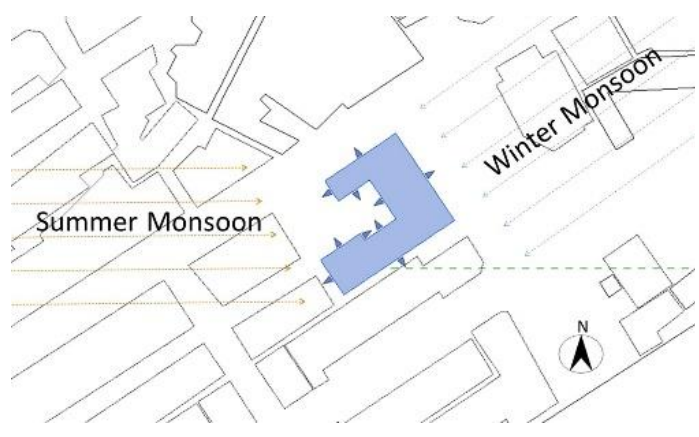

Figure 12. Schematic diagram of relationship between yearly monsoon winds and building configuration.
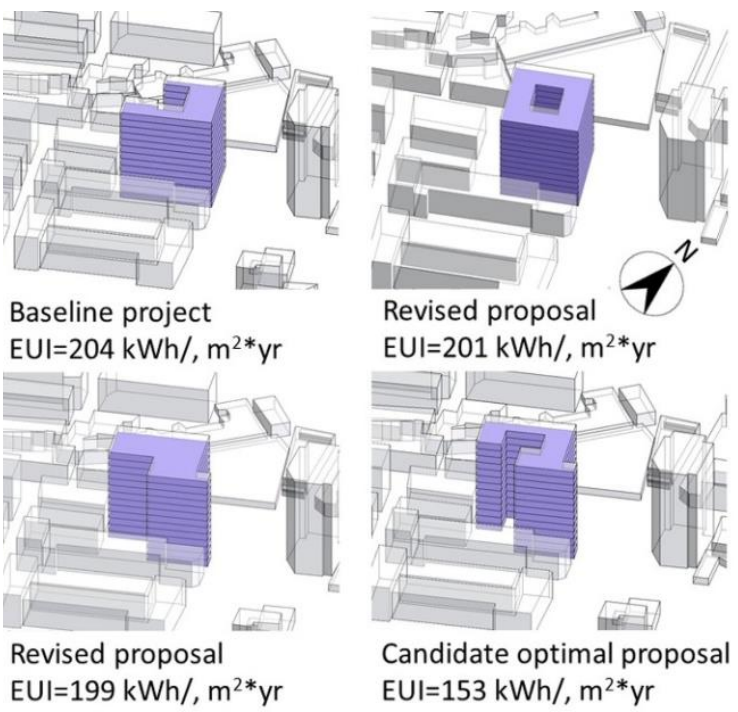

Figure 13. Continued optimization of proposal.

(8) Optimal proposal:

The candidate optimal proposal had EUI $=153 \mathrm{kWh} /, \mathrm{m} 2 \cdot \mathrm{yr}$, which represented a reduction of $51 \mathrm{kWh} /$, $\mathrm{m} 2 \cdot \mathrm{yr}$ compared with the common benchmark EUI of $198.8 \mathrm{kWh} / \mathrm{m} 2 \cdot \mathrm{yr}$. This was equivalent to a performance optimization percentage of $22.9 \%$, and met the performance optimization target of at least a $21 \%$ improvement over the ommon benchmark EUI value. A candidate optimal conceptual massing was found during the SD stage through the foregoing analysis. Taking the candidate optimal conceptual massing as a basis, the study then entered the DD stage, which involved a return to Revit modeling and repeated implementation of steps (4)-(8), with the difference that the analytical model in Step (4) employed the option of "use building elements." energy load review after revision in response to results of visualization analysis and hot spot tracking found that heat conduction through the windows and outer walls was the largest source of air conditioning load.

The following are the results of steps (7) and (8) during the DD stage:

(9) Proposal revision:

A monthly energy load review after revision in response to results of hot spot tracking found that heat conduction through the windows and outer walls was the largest source of air conditioning load. While the study originally employed a $40 \%$ percentage glazing, this was revised and reduced to $29 \%$ after the addition and revision of window elements (Figure 14). In addition, the outer walls were set as thermally insulated walls, windows were set as having two-layer LowE glass, horizontal shading eaves were placed on the southern and northern facades, and vertical shading eaves were placed on the eastern and western facades (Figure 15). 


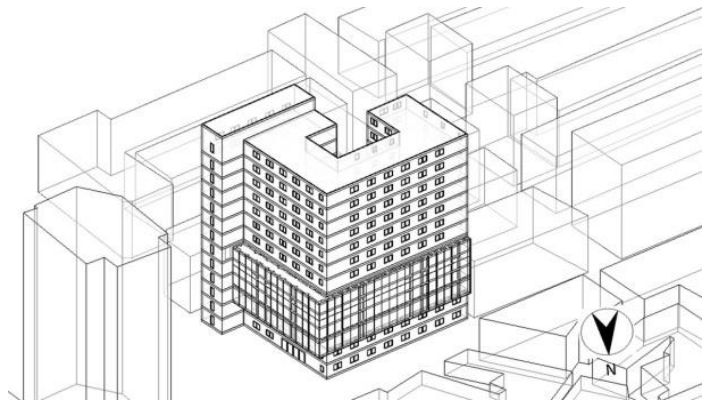

Figure 14. Addition of window elements, thermally insulated wall, and Low-E glass.

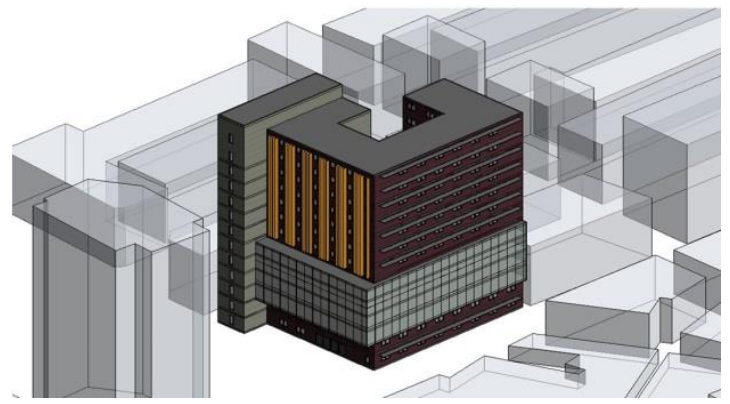

Figure 15. Addition of shading eaves.

(10) Optimal proposal:

After the optimal proposal from the conceptual massing stage entered the DD stage, and continuing improvement with regard to hot spot tracking, comparative analysis of the optimal proposal in the following tables revealed that the optimal proposal's EUI of $140 \mathrm{kWh} / \mathrm{m} 2 \cdot \mathrm{yr}$ represented a reduction of $13 \mathrm{kWh} / \mathrm{m} 2 \cdot \mathrm{yr}$ compared with the candidate optimal proposal in CD stage had EUI $=153 \mathrm{kWh} /$ $\mathrm{m} 2 \cdot \mathrm{yr}$, which was equivalent to a performance optimization percentage $8.5 \%$ (Tables $4 \& 5$ ). The performance optimization percentage met the taget setting, equal or better than $5 \%$ during the DD stage.

Table 5. Optimal proposal (SD).

\section{Energy Use Intensity}

\begin{tabular}{ll} 
Electricity EUI: & $140 \mathrm{kWh} / \mathrm{sm} / \mathrm{yr}$ \\
\hline Fuel EUI: & $132 \mathrm{MJ} / \mathrm{sm} / \mathrm{yr}$ \\
\hline Total EUI: & $636 \mathrm{MJ} / \mathrm{sm} / \mathrm{yr}$ \\
\hline
\end{tabular}

\section{Recommendations and conclusion}

Taking energy consumption throughout the building life cycle as an example, the study verified the practical effectiveness of green BIM in the case of a new Taichung hotel construction project. The following are recommendations:

A. Setting of targets:

Setting standards for energy conservation targets are not necessarily irreplaceable. In view of the fact that it is difficult to change to Taiwan Power Co. as the central power supply and billing model, this study consequently proposed the use of EUI as a target output unit. Furthermore, the "EUI values for various types of Buildings" issued by the Bureau of Energy, MOEA provides one of small number of common bechmark reference values for power usage in the Taiwan area. In theory, depending on the project's ideas and goals, there are other possible energy target standards; the applicability of these standards will depend on the direction in which the government seeks to lead industry and the feasibility and maturity of relevant technologies. Other feasible energy conservation target standards include: (1) Energy Cost Budget, (2) Net Zero Energy standards, (3) Passivhaus, (4) Peak heating or cooling [24] .

B. Validation:

The DOE-2 engine employed by GBS was developed by the Lawrence Berkeley National Laboratory, and fully passed ANSI/ASHRAE Standard 140 testing and certification in 2008. It is currently one of the most widely used optimization engines. ANSI/ASHRAE Standard 140 refers to the standard testing method for the evaluation of building energy analysis computer programs issued by the American Society of Heating and Air-Conditioning Engineers [25] . 
Green BIM emphasizes the use of building information modeling as a basic tool from the initial design stage. In addition, use of a design and analysis decision-making cycle when performing BPA in response to local climate conditions can yield optimized design proposals with good environmental effectiveness, and ultimately achieve the goal of environmental sustainability.

\section{References}

1. E. Krygiel, B. Nies, Green BIM-Successful Sustainable Design with BIM (Wiley, 2008)

2. McGraw-Hill Construction, Green BIM: How BIM is Contributing to Green Design and Construction (Smart Market Report, 2010)

3. C. M. Eastman, Building Product Models (CRC., 1999)

4. C. M. Eastman, BIM handbook: a guide to BIM for owners, managers, designers, engineers, and contractors, 2nd ed (Wiley 2008)

5. T. Kusuda,. Early history and future prospects of buildings system simulation, Proceedings of Building Simulation, 1, 3 (1999)

6. JA. Clarke, Energy Simulation in Building Design, 2nd ed, (Clarke, JA. Butterworth-Heinemann, Oxford, 2001)

7. G. Augenbroe, Building and Environment, 27(2), 149 (1992)

8. M. R. Asl, S. Zarrinmehr, M. Bergin, W. Yan, Energy and Buildings, 108, 1 (2015)

9. P. Andrasik, JNIBS, 3(4), 28 (2015)

10. J. Scade, Construction Management \& Economics, 29(4), 371 (2011)

11. Autodesk ${ }^{\circledR}$ Ecotect Analysis 2011, Available online: http://usastg.autodesk.com/adsk/servlet/download/item?siteID=123112\&id=13140033

12. Autodesk ${ }^{\circledR}$ Energy Analysis for Revit 2016, Available online: http://www.autodesk.com.tw/products/energy-analysis-revit/overview

13. Bently® Hevacomp 2016, Available online: https://www.bentley.com/en/products/brands/hevacomp

14. Tas ${ }^{\circledR}$ building modeling and simulation tool, Available online: http://www.buildup.eu/tools/34288

15. Graphisoft巴 Eco Designer STAR 2016, Available online: http://www.graphisoft.com/archicad/ecodesigner_star/

16. T. Maile, M. Fischer, V. Bazjanac, Building Energy Performance Simulation Tools - a Life-Cycle and Interoperable Perspective, (Stanford University, Available online: http://cife.stanford.edu/node/169, 2007)

17. Autodesk ${ }^{\circledR} 2016$, Energy Analysis Workflows, Autodesk ${ }^{\circledR}$ Building Performance Analysis Help, Available online:

http://help.autodesk.com/view/BUILDING_PERFORMANCE_ANALYSIS/ENU/?guid=GUIDE85A114E-BA0D-4811-B1A5-4EE26462708A

18. LEED 2016. Available online: http://www.usgbc.org/leed

19. Taiwan Power Cost and Price tips, Available online: http://www.taipower.com.tw/content/new_info/new_info-d11.aspx?LinkID=14

20. Chung, W., Applied Energy, 8(5), 1470 (2011)

21. R. L. Huang, EUI Values for Various types of Buildings, Building Energy Conservation Applied Technical Handbook (Bureau of Energy, MOEA, 2013), Available online: http://ecct.tgpf.org.tw/print/files/1021231\%E5\%BB\%BA\%E7\%AF\%89\%E7\%AF\%80\%E8\%83 $\%$ BD $\%$ E6\%8A\%80\%E8\%A1\%93\%E6\%89\%8B\%E5\%86\%8A.pdf

22. S. Malkin, Weather data for Building Energy Analysis, (Autodesk, Inc. 2008), Available online: https://sustainabilityworkshop.autodesk.com/sites/default/files/core-pagefiles/weather_data_greenbuildingstudio_adsk_white_paper.pdf

23. K. Anderson, Energy Model, Design Energy Simulation for Architects Guild to $3 D$ graphics, $1 \mathrm{st}$ ed., (Fuller, W., Ed; Routledge: New York and Landon, 2014) 
24. K. Anderson, Planning and Goal-Setting, Design Energy Simulation for Architects Guild to 3D graphics, 1st ed., (Fuller, W., Ed; Routledge: New York and Landon, 2014)

25. Autodesk ${ }^{\circledR}$ 2016, Green Building Studio Validation, Autodesk BPA Help, Available online: $\mathrm{http}$ ://help.autodesk.com/view/BUILDING_PERFORMANCE_ANALYSIS/ENU/?guid=GUIDEF68E7D5-C0A5-4805-BFE5-7C74C57B712E 